Technical Papers

\title{
$\mathrm{MR}$ 댐퍼를 이용한 대형 버스 현가장치의 반능동 제어
}

\author{
윤호상*, 문일동 ${ }^{+}$, 김재원 $^{++}$, 오재윤 $^{++}$, 이형원 $^{+++}$
}

(Manuscript received: Jan, 13, 2012 / Revised: Mar, 30, 2012 / Accepted: Apr, 6, 2012)

\section{Semi-Active Control of a Suspension System with a MR Damper of a Large-sized Bus}

\author{
Hosang Yoon*, Ildong Moon ${ }^{+}$Jaewon Kim ${ }^{++}$, Chaeyoun $\mathrm{Oh}^{+++}$, Hyungwon Lee ${ }^{++++}$
}

\begin{abstract}
In this work, the semi-active control of a large-sized bus suspension system with an MR damper was studied. An MR damper model that can aptly describe the hysteretic characteristics of an MR damper was adopted. Parameter values of the MR damper model were suitably modified by considering the maximum damping force of a passive damper used in the suspension system of a real large-sized bus. In addition, a fuzzy logic controller was developed for semi-active control of a suspension system with an MR damper. The vertical acceleration at the attachment point of the MR damper and the relative velocity between sprung and unsprung masses were used as input variables, while voltage was used as the output variable. Straight-ahead driving simulations were performed on a road with a random road profile and on a flat road with a bump. In straight-ahead driving simulations, the vertical acceleration and pitch angle were measured to compare the riding performance of a suspension system with a passive damper with that of a suspension with an MR damper. In addition, a single lane change simulation was performed. In the simulation, the lateral acceleration and roll angle were measured in order to compare the handling performance of a suspension system using a passive damper with that of a suspension system using an MR damper.
\end{abstract}

Key Words : Semi-active control(반능동 제어), MR damper(MR 댐퍼), Large-sized bus(대형버스), Computational model(컴퓨터 모델), Fuzzy logic control(퍼지 제어), Ride comfort(승차성능), Handling(핸들링), Random road profile(불규칙 노면), Single lane change(단일 차선 변경)

\section{1. 서 론}

차량에 사용되는 현가장치는 차량의 자세를 적절히 유지하고 조종안정성을 위해 타이어와 노면 사이에 지속적이고 일정한
접촉을 유지하는 기능을 가지고 있다. 또한 노면의 불균일함으 로부터 발생하는 차체의 진동을 억제하여 승차감을 향상시키 는 기능도 가지고 있다. 따라서 현가장치는 차량의 승차성능과 핸들링 성능 두 가지 측면에 매우 중요한 영향을 미친다. 기존

\footnotetext{
* (주)현 대자동차 남양연구소

$+\quad$ (주)대한항공항공기술연구소

$++\quad$ 전북대학교 대학원 바이오나노시스템공학과

++ 교신저자, 전북대학교 기계시스템공학부 (ohcy@jbnu.ac.kr)

주소: 561-756 전북 전주시 덕진구 백제대로 567

++++ 전북대학교 대학원 기계시스템공학과
} 
의 수동 현가장치를 이용하여 승차성능과 핸들링 성능을 동시 에 향상시키기에는 많은 어려움이 있다. 최근 들어 승차성능과 핸들링 성능을 동시에 개선하기 위하여 능동 현가장치나 반능동 현가장치를 사용하고 있다. 능동 현가장치의 경우는 고가이고 매우 복잡한 구조로 인하여 제작에 어려움이 있다. 그러나 반능동 현가장치는 상대적으로 저가이고 단순한 구조를 가지고 있으 면서도 승차감 및 조종안정성을 동시에 향상시킬 수 있다. 따라서 반능동 현가장치의 적용에 관한 많은 연구가 이루어지고 있다.

MR(Magnetorheological) 유체는 자기장의 세기에 따라서 항복응력이 변하는 점소성 거동을 한다. 그리고 $\mathrm{MR}$ 유체는 비 교적 작은 에너지원으로 우수한 감쇠력을 얻을 수 있고, 빠른 반응속도를 가지며, 외부 온도가 변하거나 불순물이 첨가되어 도 항복응력의 변화가 거의 없이 일정한 성능을 유지할 수 있다. 따라서 MR 유체를 매체로 사용하는 MR 댐퍼를 이용하여 차 량의 반능동 현가장치를 개발하고자 하는 연구가 활발하게 수 행되고 있다 ${ }^{(1 \sim 7)}$.

반능동 제어 현가장치도 능동 현가장치와 거의 유사한 승차 성능을 발휘할 수 있다는 연구 결과가 발표되었다 ${ }^{(2)}$. 남은 운전 석에 MR 댐퍼를 적용하여 스카이 훅 제어를 수행하였으며 ${ }^{(1)}$, $\mathrm{MR}$ 댐퍼를 장착한 $1 / 4$ 차량 모델에 스카이 훅 제어알고리즘을 적용하여 수동 댐퍼에 비해 성능이 향상됨을 보여주는 결과가 발표되었다 ${ }^{(3)}$. 하지만, MR 댐퍼에 가해지는 전류의 출력인자가 Max., Min. 값으로 한정되어 성능 향상에는 한계가 있었다. 1/4 차량 모델에 시험을 통하여 구한 MR 댐퍼의 모델과 피드백 제 어기를 적용한 반능동 현가장치에 관한 연구도 수행되었다 ${ }^{(4,6)}$. 또한 7자유도의 전체 차량 모델을 이용하여 $\mathrm{MR}$ 댐퍼가 장착된 HILS장비와 연동을 통해 반능동 현가장치의 최적 제어기법에 대한 연구도 수행되었다 ${ }^{(7)}$. 이와 같이 지금까지 이루어진 MR 댐퍼를 적용한 반능동 현가장치에 관한 대부분의 연구에서는 주로 차량을 $1 / 4$ 차 혹은 $1 / 2$ 차로 단순화한 모델을 이용하여 차 량의 롤 운동과 피치운동을 표현하기가 어려웠다. 그리고 $\mathrm{MR}$ 댐퍼의 사용 범위를 축소하거나 감쇠력 특성 곡선을 단순화하 여 연구를 수행하여 MR 댐퍼가 가지는 다양한 성능을 완전하 게 검증하지 못하였다. 또한 MR 댐퍼를 이용한 반능동 현가장 치에 관한 연구는 주로 승용차에 국한되어 이루어졌다.

본 논문에서는 MR 댐퍼를 장착한 대형버스의 반능동 현가장 치에 관한 연구를 수행한다. 다물체 동역학 소프트웨어인 MSC. $\mathrm{ADAMS}^{(8)}$ 를 이용하여 에어 스프링이 장착된 대형버스의 전체 차량 모델을 개발한다. 또한 MATLAB/SIMULINK ${ }^{(9)}$ 를 이용하 여 MR 댐퍼 모델과 MR 댐퍼의 반능동 제어를 위한 퍼지 제어 알고리즘을 구현한다. 기존의 수동 현가장치가 장착된 대형 버스 모델과 MR 댐퍼를 이용한 반능동 현가장치를 장착한 대형 버스 모델의 승차성능과 핸들링 성능을 비교하기 위하여 불규칙 노 면과 범프 노면 및 단일 차선 변경 주행 모의시험을 수행한다.

\section{MR 댐퍼 모델링}

본 논문에서는 작은 크기의 속도 구간을 가장 잘 묘사하고 $\mathrm{MR}$ 댐퍼가 가지는 이력특성을 잘 표현하는 것으로 알려지고 있는 식 (1)-(7)로 표현되는 개량된 Bouc-Wen모델 ${ }^{(11)}$ 을 사용 하여 MR 댐퍼의 이력거동을 나타내었다.

$$
\begin{aligned}
& F=a z+c_{0}(\dot{x}-\dot{y})+k_{0}(x-y)+k_{1}\left(x-x_{0}\right) \\
& z=-x|x-y| z|z|^{n-1}-\beta(x-y)|z|^{n}+A(\dot{x}-\dot{y}) \\
& \dot{y} \frac{1}{c_{0}+c_{1}}\left\{\alpha z+c_{0} x+k_{0}(x-y)\right\} \\
& \alpha=\alpha_{a}+\alpha_{b} \mu \\
& c_{1}=c_{1 a}+c_{1 b} \mu \\
& c_{0}=c_{0 a}+c_{0 b} \mu \\
& \dot{\mu}=-\eta(\mu-\nu)
\end{aligned}
$$

위 식들에서 $\mathrm{x}$ 는 댐퍼 양단의 변위이고, $\mathrm{y}$ 는 $\mathrm{MR}$ 댐퍼의 유사 변위(pseudo displacement)이며, $\alpha$ 는 내부변수 $\mathrm{z}$ 와 관련된 계수 이다. $x_{0}$ 는 댐퍼의 초기 변위이고, $c_{0}$ 와 $k_{0}$ 는 높은 속도에의 점성 감쇠와 강성이고, $c_{1}$ 은 낮은 속도에서의 점성 감쇠이고, $k_{1}$ 은 압축시의 매우 작은 감쇠력과 관련된 강성이다. $\alpha, c_{0}, c_{1}$ 은 반능동 제어시 MR댐퍼의 이력 거동 특성을 표현해주는 변수들이다. $\gamma, \beta, A$ 는 시간 이력 변수이다.

본 논문에서는 전방 현가장치에 사용된 MR댐퍼의 경우 참고 문헌 ${ }^{(1)}$ 에서 제안한 값을 사용하였다. 그러나 후방 현가장치에 사용된 MR댐퍼는 실제 버스에 사용되는 댐퍼의 감쇠력과 비 슷한 정도의 최대 감쇠력을 발휘 할 수 있도록 하기 위해서 개 량된 Bouc-Wen모델식의 변수 값을 수정하여 이용하였다. 전 방과 후방 현가장치에 사용한 MR댐퍼의 모델식을 구성하는 변수 값들은 Table 1에 정리하여 나타내었다. 본 논문에서는 식 (1)-(7)과 Table 1으로 표현되는 개량된 Bouc-Wen모델을 MATAB/Simulink ${ }^{(9)}$ 를 이용하여 구현하였다.

\section{3. 대형버스 모델링}

본 논문에서는 대형 버스 전체 차량 컴퓨터 모델을 MSC. $\mathrm{ADAMS}$ 를 이용하여 개발하였다. Fig. 1는 본 논문에서 개발한 대형버스 컴퓨터 모델을 보여 준다. 이 그림이 보여주는 바와 
같이 대형버스 전체 차량 컴퓨터 모델을 크게 버스 바디, 전,후방 현가장치, 파워트레인으로 구성하였다. 조향 장치를 포함하는 전방 현가 장치는 전방차축, 새클, 피트만 암, 드래그 링크, 타이 로드와 아래 토크 로드, 위 토크 로드와 에어 스프링 및 댐퍼 등 으로 구성되었다. 전방현가장치에는 댐퍼와 에어 스프링이 각각 2 개씩 사용 되었다. 조향장치를 포함하는 전방 현가 장치의 너클 을 액슬과 회전 조인트로 연결하였고 타이로드는 너클과 구 조 인트로 연결하였다. 스테빌라이져바와 어퍼 토크로드, 로어 토크 로드는 바디와 부싱으로 고정하였다. 현가장치의 피트만 암은 전방 드래그 링크와 구 조인트로 연결하였고, 전방 드래그 링크는 링크 암과 유니버셜 조인트로 연결하였으며, 링크 암은 후방 드래그 링크와 구 조인트로 연결하였다. 후방 드래그 링크는 너클 과 유니버셜 조인트로 연결하여 피트만 현가장치를 구현하였다.

후방 현가장치는 댐퍼와 에어 스프링이 각각 4개씩 사용되었 다. 레이디어스 로드와 토크 로드는 각각 바디와 리어 엑슬에

Table 1 Parameters for the modified Bouc-Wen model ${ }^{(11)}$

\begin{tabular}{c|c|c|c}
\hline \hline \multicolumn{2}{c|}{ Front (Modified) MR damper } & \multicolumn{2}{c}{ Rear MR Damper } \\
\hline parameter & value & parameter & value \\
\hline$C_{\mathrm{Oa}}$ & $21 \mathrm{~N} \cdot \mathrm{sec} / \mathrm{cm}$ & $C_{\mathrm{Oa}}$ & $21 \mathrm{~N} \cdot \mathrm{sec} / \mathrm{cm}$ \\
\hline$C_{\mathrm{Ob}}$ & $3.5 \mathrm{~N} \cdot \mathrm{sec} / \mathrm{cm} \cdot \mathrm{V}$ & $C_{\mathrm{Ob}}$ & $3.5 \mathrm{~N} \cdot \mathrm{sec} / \mathrm{cm} \cdot \mathrm{V}$ \\
\hline$k_{\mathrm{O}}$ & $46.9 \mathrm{~N} / \mathrm{cm}$ & $k_{\mathrm{O}}$ & $46.9 \mathrm{~N} / \mathrm{cm}$ \\
\hline$c_{1 \mathrm{a}}$ & $283 \mathrm{~N} \cdot \mathrm{sec} / \mathrm{cm}$ & $c_{1 \mathrm{a}}$ & $283 \mathrm{~N} \cdot \mathrm{sec} / \mathrm{cm}$ \\
\hline$c_{1 \mathrm{~b}}$ & $2.95 \mathrm{~N} \cdot \mathrm{sec} / \mathrm{cm} \cdot \mathrm{V}$ & $c_{1 \mathrm{~b}}$ & $2.95 \mathrm{~N} \cdot \mathrm{sec} / \mathrm{cm} \cdot \mathrm{V}$ \\
\hline$k_{1}$ & $7 \mathrm{~N} / \mathrm{cm}(5)$ & $k_{1}$ & $5 \mathrm{~N} / \mathrm{cm}$ \\
\hline $\mathrm{x}_{\mathrm{O}}$ & $14.3 \mathrm{~cm}$ & $\mathrm{x}_{\mathrm{O}}$ & $14.3 \mathrm{~cm}$ \\
\hline$\alpha_{\mathrm{a}}$ & $420 \mathrm{~N} / \mathrm{cm}$ & $\alpha_{\mathrm{a}}$ & $140 \mathrm{~N} / \mathrm{cm}$ \\
\hline$\alpha_{\mathrm{b}}$ & $895 \mathrm{~N} / \mathrm{cm} \cdot \mathrm{V}$ & $\alpha_{\mathrm{b}}$ & $695 \mathrm{~N} / \mathrm{cm} \cdot \mathrm{V}$ \\
\hline$\gamma$ & $158 \mathrm{~cm} \mathrm{c}^{-2}$ & $\gamma$ & $363 \mathrm{~cm}^{-2}$ \\
\hline$\beta$ & $158 \mathrm{~cm}{ }^{-2}$ & $\beta$ & $363 \mathrm{~cm}^{-2}$ \\
\hline $\mathrm{A}$ & 332 & $A$ & 301 \\
\hline $\mathrm{n}$ & 2 & $\mathrm{n}$ & 2 \\
\hline$\eta$ & $190 \mathrm{sec}$ & $\eta$ & $190 \mathrm{sec}^{-1}$ \\
\hline
\end{tabular}

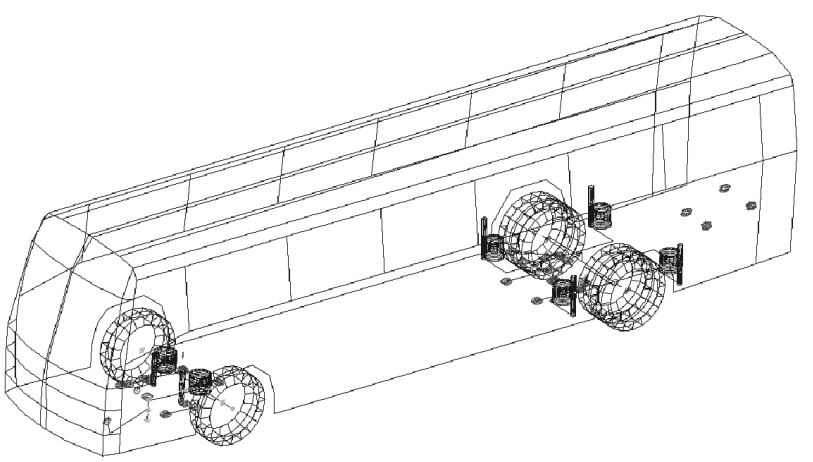

Fig. 1 Computational model for a large-sized bus
부싱으로 연결하였다. 스테빌라이저 바는 회전조인트를 이용 하여 리어 액슬과 연결하였으며, 좌우 스테빌라이저 로드와는 구 조인트로 연결하였다. 스테빌라이저 로드는 바디와 부싱으로 연결하였다. 엔진과 트랜스미션으로 구성되는 파워트레인은 강체로 모델링하였으며 바디와 부싱 요소를 이용하여 연결하 였다. 대형 버스를 이루는 여러 부속 시스템은 각각의 질량을 서로 더하여 무게 중심점에 추가함으로써 전체 차량 컴퓨터 모

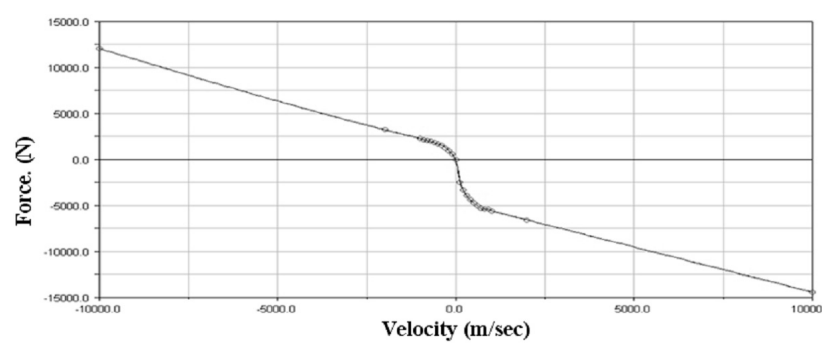

(a) front passive damper

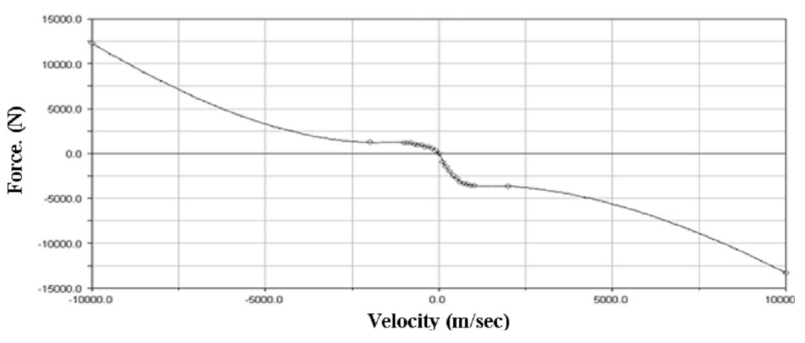

(b) rear passive damper

Fig. 2 Measured nonlinear characteristics of a passive damper: (a) front passive damper (b) rear passive damper

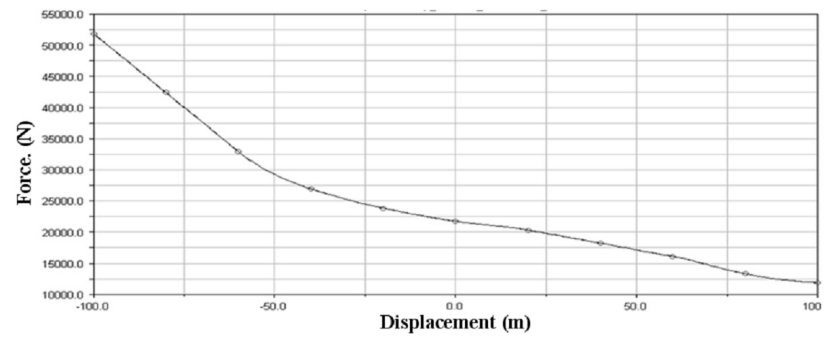

(a) front air spring

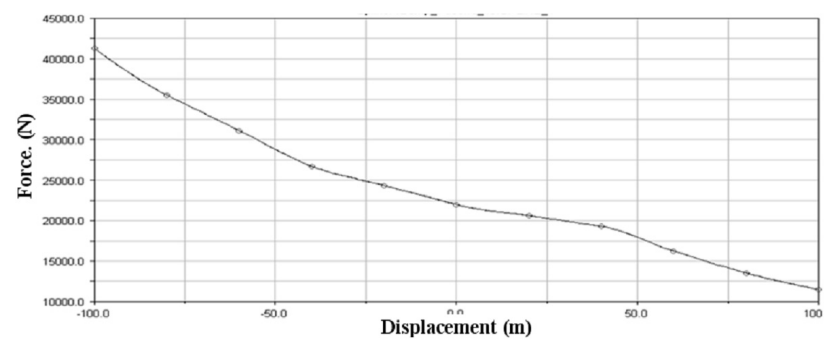

(b) rear air spring

Fig. 3 Measured nonlinear characteristics of an air spring: (a) front air spring (b) rear air spring 
델을 구성하였다.

Fig. 2은 단품시험을 통하여 구한 전방현가장치와 후방현가 장치에 사용된 수동 댐퍼의 속도와 감쇠력의 관계를 보여준다. 이와 같이 비선형적인 특성을 보이는 수동 댐퍼의 감쇠력은 MSC.ADAMS 스프라인 함수를 이용하여 모델링 하였다.

Fig. 3는 단품시험을 통하여 구한 전방현가장치와 후방현가 장치에 사용된 에어 스프링의 변위와 탄성력 관계를 보여준다. 이와 같이 비선형적인 특성을 보이는 에어스프링의 탄성력은 MSC.ADAMS 스프라인 함수를 이용하여 모델링하였다.

타이어 모델은 차량의 조종성 및 승차감 해석에 결정적인 영 향을 미치는 가장 중요한 인자 중의 하나이다. 본 논문에서는 MSC.ADAMS/TIRE ${ }^{(8)}$ 에서 제공하는 FIALA 타이어 모델을 사용하였다. FIALA 타이어 모델에서 필요한 데이터는 실험을 통해 구하였다. 본 논문에서 사용한 타이어는 11.00-22.5 레디 알 타이어이다.

\section{4. 퍼지 제어기}

반능동현가장치는 다양한 기법을 이용하여 제어할 수 있다. 본 논문에서는 반능동 현가장치에 사용되는 $\mathrm{MR}$ 댐퍼의 제어를 위해서 퍼지 논리 제어 기법을 사용하였으며 MATLAB/Fuzzy logic Toolbox ${ }^{(10)}$ 를 사용하여 구현하였다. MR 댐퍼 반능동 제 어에 사용되는 퍼지 제어기의 입력 변수로 본 논문에서는 MR 댐퍼 장착지점에서 스프링 상 질량의 Z축 방향 가속도와 스프 링 상 질량과 하 질량 사이의 상대 속도를 선정하였다. 이 같은 입력 변수의 범위는 실제 작동 범위를 조사하여 각각 [-700. $700]$ 과 $[-500,500]$ 으로 설정하였다. 출력 변수로는 MR 댐퍼 의 감쇄력을 결정하는 전압 값 $(\mathrm{V})$ 을 사용하였다. 출력 변수는 $\mathrm{MR}$ 댐퍼의 가용 전압 범위인 $[-3,3]$ 으로 설정하였다.

본 논문에서는 Mamdani-type 추론법을 이용하여 주여진 입력 값에 따른 출력 값을 추론하였다. 소속 함수는 삼각형과 사다리 꼴 함수를 혼합하여 사용하였다. 전방과 후방 현가장치에서 입력 변수의 소속함수는 같은 형태로 하였다. 대형 버스에서는 전방과 후방 차축의 하중 지지 정도에 많은 차이가 있다. 이 같은 상황을 고려하여 전방과 후방 현가장치에서는 출력 변수인 전압의 소속 함수 형태는 달리 하였다. Fig. 4는 전방과 후방 현가장치에 사용 된 MR 댐퍼 입력변수인 상대속도와 가속도의 소속함수를 보 여준다. 그리고 Fig. 5은 전방과 후방 현가장치에 사용된 MR 댐퍼 출력변수 소속함수를 보여준다.

퍼지 제어 룰은 댐퍼가 리바운드(rebound) 할 때는 낮은 전압 값을 출력하고MR 댐퍼가 자운스(jounce) 할 때는 높은 전압 값을 출력하여 차량의 피치(pitch), 히브(heave), 롤(roll)을 억제 하는 하도록 설계하였다. 또한 스프링 상 질량의 절대 가속도와 스프링 상 질량과 하 질량 사이의 상대 속도를 곱한 값이 양이
되는 구간에서는 높은 전압 값을 출력하고 음이 되는 구간에서 는 상대적으로 낮은 전압 값을 출력 하도록 퍼지 룰을 설계하였 다. Table 2는 전방 및 후방 MR damper 퍼지 제어를 위한 퍼지 제어법칙 표를 보여준다.

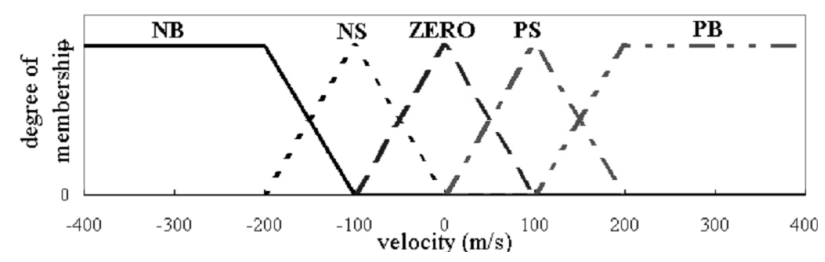

(a) relative velocity

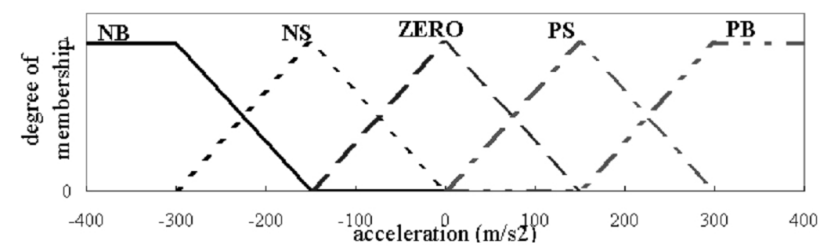

(b) acceleration

Fig. 4 Fuzzy input membership function for (a) relative velocity and (b) acceleration

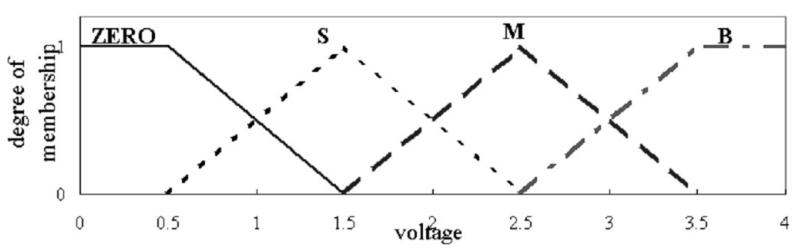

(a) front damper

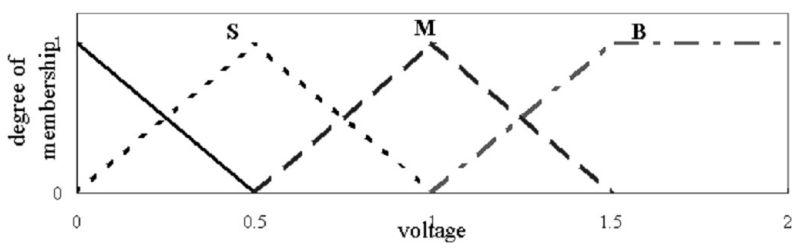

(b) rear damper

Fig. 5 Fuzzy output membership function for (a) the front damper and (b) the rear damper

Table 2 Fuzzy rule table for the front and rear MR damper

\begin{tabular}{c|c|c|c|c|c}
\hline $\begin{array}{c}\text { Ver. Accel } \\
\text { Rel. vel. }\end{array}$ & $\mathrm{NB}$ & $\mathrm{NS}$ & $\mathrm{ZE}$ & $\mathrm{PS}$ & $\mathrm{PB}$ \\
\hline $\mathrm{NB}$ & $\mathrm{B}$ & $\mathrm{M}$ & $\mathrm{S}$ & $\mathrm{ZE}$ & $\mathrm{ZE}$ \\
\hline $\mathrm{NS}$ & $\mathrm{M}$ & $\mathrm{S}$ & $\mathrm{ZE}$ & $\mathrm{ZE}$ & $\mathrm{ZE}$ \\
\hline $\mathrm{ZE}$ & $\mathrm{S}$ & $\mathrm{ZE}$ & $\mathrm{ZE}$ & $\mathrm{S}$ & $\mathrm{S}$ \\
\hline $\mathrm{PS}$ & $\mathrm{ZE}$ & $\mathrm{ZE}$ & $\mathrm{ZE}$ & $\mathrm{S}$ & $\mathrm{M}$ \\
\hline $\mathrm{PB}$ & $\mathrm{ZE}$ & $\mathrm{ZE}$ & $\mathrm{S}$ & $\mathrm{M}$ & $\mathrm{B}$ \\
\hline
\end{tabular}




\section{5. 모의시험을 통한 성능 검증}

본 논문에서는 대형버스 전체 차량의 컴퓨터 모델을 MSC. $\mathrm{ADAMS}$ 를 이용하여 개발하였다. 그리고 MR 댐퍼의 모델식은 MATLAB/Simulink를 이용하여 구현하였으며, MR 댐퍼의 반 능동 제어를 위한 퍼지 논리 제어는 MATLAB/Fuzzy logic Toolbox를 이용하여 구현하였다. MSC.ADAMS/Control 모듈

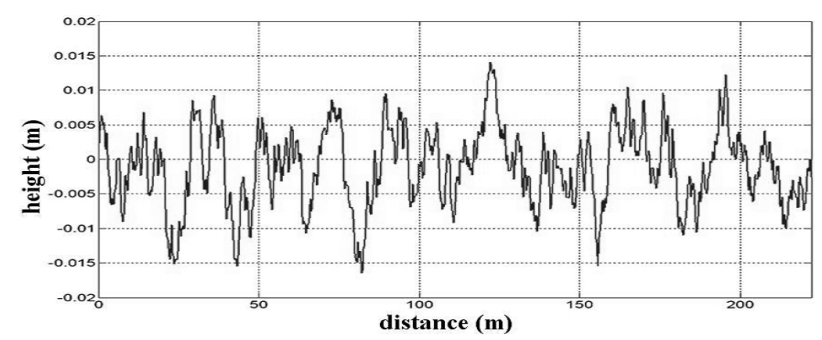

Fig. 6 Random road profile

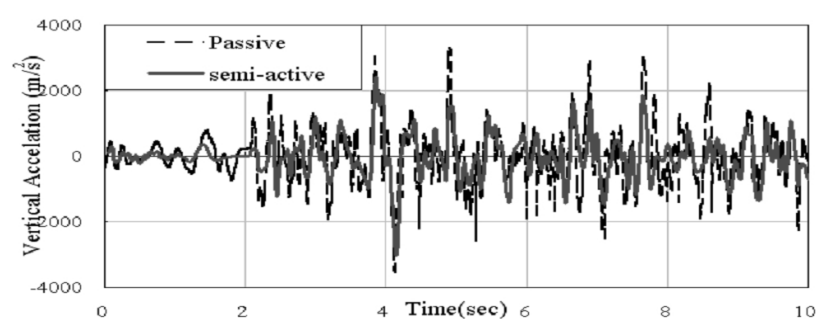

(a) vertical acceleration in the time domain

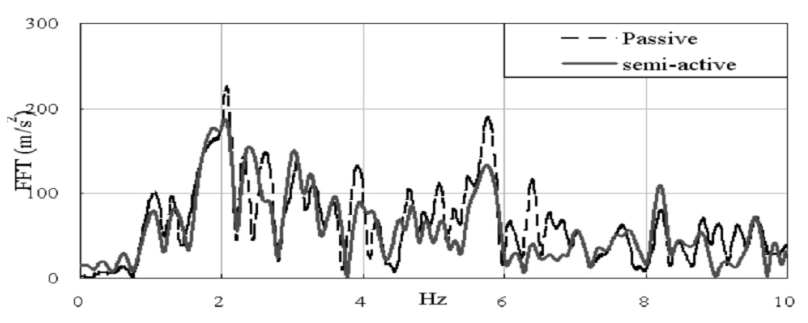

(b) vertical acceleration in the frequency domain

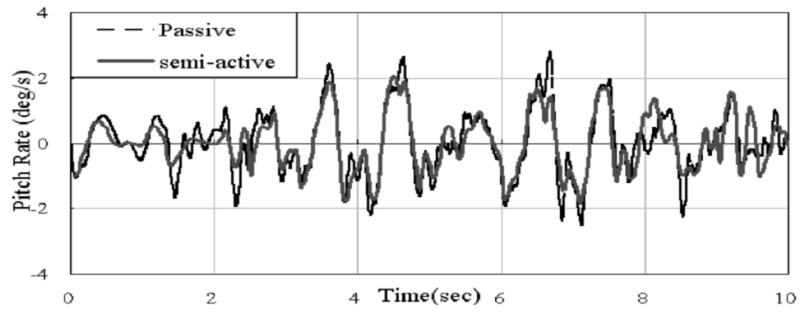

(c) pitch angle

Fig. 7 Simulation results obtained with a random road profile at speed of $70 \mathrm{~km} / \mathrm{h}$ : (a) vertical acceleration at the center of mass in the time domain (b) vertical acceleration at the center of mass in the frequency domain (c) pitch angle at the center of mass
을 이용하여 차량 모델과 MR 댐퍼 모델 및 MR 댐퍼 제어기를 인터페이스하여 통합된 모델을 완성하였다. 차량 모델로부터 구한 스프링 상 질량 수직 가속도와 스프링 상 질량과 스프링 하 질량 사이의 상대속도가MR 댐퍼 퍼지 제어기에 입력으로 제 공된다. MR 댐퍼 퍼지 제어기의 출력이 MR 댐퍼 모델에 입력 으로 제공되면 댐핑력을 계산하여 차량 모델에 제공하게 된다.

본 논문에서는 수동 현가장치와 MR댐퍼를 이용한 반능동 현가장치의 승차성능 및 핸들링 성능을 비교하기 위한 모의시 험을 수행하였다. 먼저 승차 성능을 비교하기 위한 불규칙 노면 을 주행하는 모의시험을 수행하였다. 불규칙 노면 주행 모의시 험에서 차량은 $70 \mathrm{~km} / \mathrm{h}$ 와 $60 \mathrm{~km} / \mathrm{h}$ 의 속도로 등속 주행을 하였 다. 차량의 직진 주행을 보장하기 위해서 조향 휠은 고정한 상 태에서 주행을 하였다. 그리고 버스에는 승객들이 탑승하지 않 은 상태의 하중 조건을 사용하였다. 본 논문에서는 Fig. 6 과 같 은 거리에 따른 노면의 높이가 불규칙한 노면을 구성하여 모의 시험에 이용하였다 ${ }^{(12)}$.

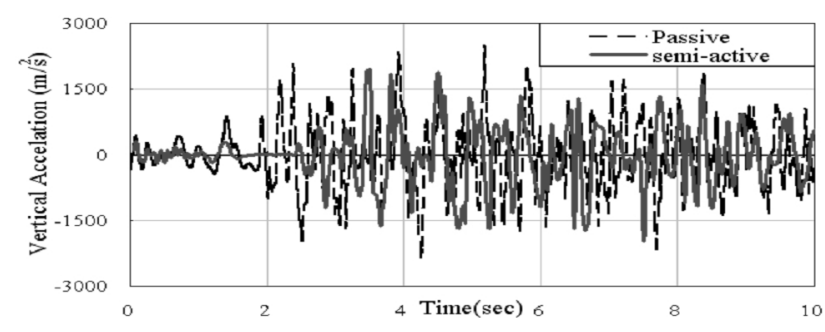

(a) vertical acceleration in the time domain

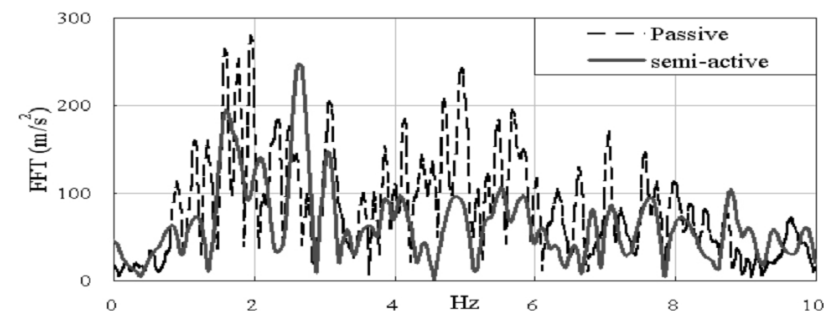

(b) vertical acceleration in the frequency domain

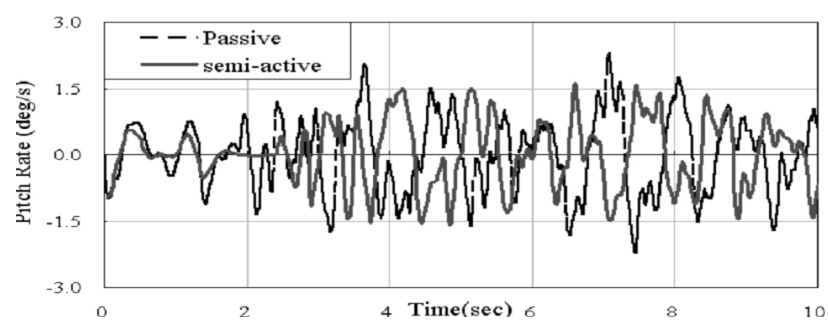

(c) pitch angle

Fig. 8 Simulation results obtained with a random road profile at a speed of $60 \mathrm{~km} / \mathrm{h}$ : (a) vertical acceleration at the center of mass in the time domain (b) vertical acceleration at the center of mass in the frequency domain (c) pitch angle at the center of mass 
모의시험을 수행하는 동안에 차량의 무게 중심점에서 $\mathrm{z}$ 축 방 향의 수직 가속도와 피치 각을 측정하였다. Fig. 7과 Fig. 8는 각각 $70 \mathrm{~km} / \mathrm{h}$ 와 $60 \mathrm{~km} / \mathrm{h}$ 의 속도로 처음 2 초 동안 평평한 노면 을 주행한 후 Fig. 6의 불규칙 노면을 8초 동안 주행하였을 때 의 결과를 보여준다. Fig. 7(a)와 Fig. 8(a)는 MR 댐퍼를 장착 한 차량과 수동댐퍼를 장착한 차량의 수직가속도를 시간 대역 에서 비교하여 보여준다. 이 그림들에서 보여주는 바와 같이 $\mathrm{MR}$ 댐퍼를 장착한 차량의 진폭이 수동 댐퍼를 장착한 차량보 다 작았다. Fig. 7(b)와 Fig. 8(b)는 수직 가속도 반응을 주파수 대역에서 비교하여 보여준다. 이 그림에서도 MR 댐퍼를 장착 한 차량이 수동 댐퍼를 장착한 차량에 비해 거의 모든 주파수 영역에서 진폭이 작았다. 특히 차량 속도가 $60 \mathrm{~km} / \mathrm{h}$ 일 때 제진 효과가 뚜렷함을 보였다. Fig. 7(c)와 Fig. 8(c)에서 보여주는 바와 같이 피치 각도 $\mathrm{MR}$ 댐퍼를 장착한 차량의 진폭이 수동 댐퍼를 장착한 차량보다 작았다.

본 논문에서는 대형 버스가 범프를 통과하는 모의시험을 수 행하여 갑작스런 외부 입력이 가해졌을 때 수동 현가장치를 장

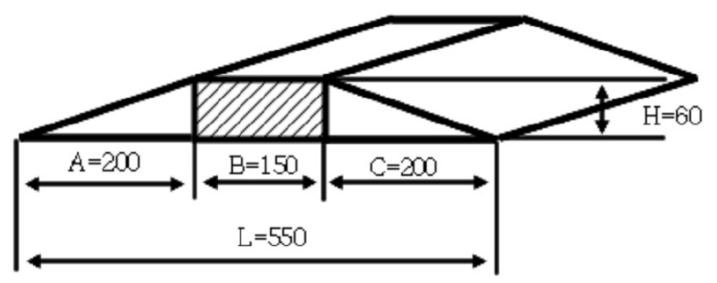

Fig. 9 Dimensions of the bump used in the double wheel bumpy ride simulation (units $=\mathbf{m m}$ )

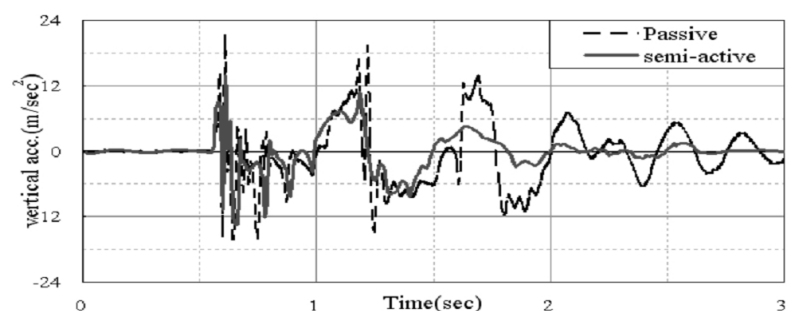

(a) vertical acceleration

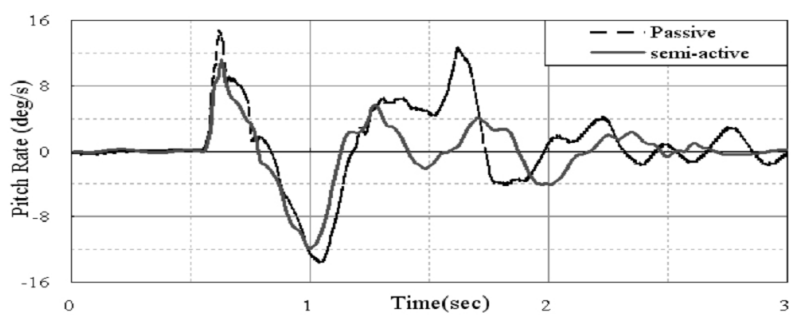

(b) pitch angle

Fig. 10 Double wheel bumpy ride simulation results obtained at a speed of $40 \mathrm{~km} / \mathrm{h}$ : (a) vertical acceleration at the center of mass (b) pitch angle at the center of mass
착한 차량과 $\mathrm{MR}$ 댐퍼를 이용한 반능동 현가장치를 장착한 차 량의 승차 성능을 비교해 보았다. 본 논문에서는 상용차 승차감 평가를 위한 범프 통과 시험에 통상적으로 이용되는 Fig. 9에 보여지는 바와 같은 높이가 $60 \mathrm{~mm}$ 인 범프를 사용하였다. Fig. $10 \mathrm{Fig}$. 11 은 각각 $40 \mathrm{~km} / \mathrm{h}$ 와 $30 \mathrm{~km} / \mathrm{h}$ 의 속도로 범프 통과 모의 시험을 수행한 결과를 비교하여 보여주고 있다. 수동 댐퍼를 장착한 차량과 $\mathrm{MR}$ 댐퍼를 장착한 차량의 승차 성능을 비교하 기 위해 차량의 무게 중심점에서 $\mathrm{z}$ 축 방향의 수직 가속도와 피 치 각속도를 모의시험을 수행하면서 측정하였다. $40 \mathrm{~km} / \mathrm{h}$ 와 $30 \mathrm{~km} / \mathrm{h}$ 의 속도에서 최대 수직 가속도 뿐 아니라 최대 피치 각 속도가 MR 댐퍼를 장착한 차량이 수동 댐퍼를 장착한 차량보 다 작은 진폭을 보여주었다. 상하 진동 뿐 아니라 피치 모션이 $\mathrm{MR}$ 댐퍼를 장착한 차량이 수동 댐퍼를 장착한 차량보다 빨리 안정화 되었다. 특히, $30 \mathrm{~km} / \mathrm{h}$ 로 주행하는 경우 보다 $40 \mathrm{~km} / \mathrm{h}$ 로 주행하는 경우가 MR 댐퍼의 상하 진동 및 피치 모션 제진 성 능이 좀 더 우수하였다.

수동 댐퍼를 장착한 차량과 $\mathrm{MR}$ 댐퍼를 장착한 차량의 핸들 링 성능을 비교하기 위해서 단일차선변경 모의시험을 실시하 였다. 단일차선변경 모의시험은 $70 \mathrm{~km} / \mathrm{h}$ 의 속도로 평평한 노면 에서 수행하였다. 단일차선변경 모의시험에서 조향 입력은 휠 에 직접 가하지 않고 스티어링 기어 박스에 입력하여 입력된 값이 너클을 통해 휠에 전달되어 차선변경이 이루어지도록 하 였다. Fig. 12(a)는 대형 버스 단일차선변경 모의시험을 수행하 였을 때 차량의 횡 방향 궤적을 보여준다. 이 그림에서 보여주 는 바와 같이 차량 출발 후 2초 되는 시점에 조향 입력을 가하 여 3 초 되는 시점에 차선을 변경하도록 하였다. 그리고 Fig.

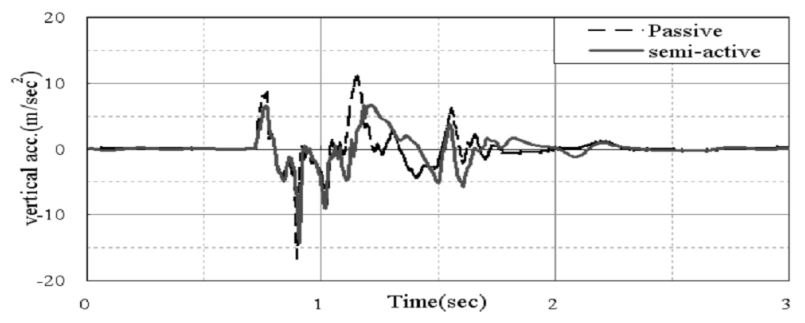

(a) vertical acceleration

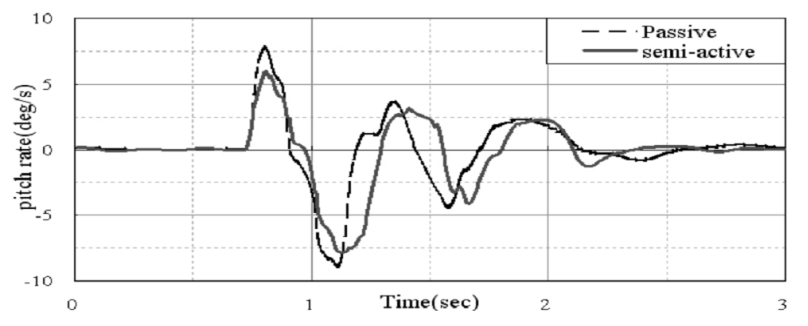

(b) pitch angle

Fig. 11 Double wheel bumpy ride simulation results obtained at a speed of $30 \mathrm{~km} / \mathrm{h}$ : (a) vertical acceleration at the center of mass (b) pitch angle at the center of mass 


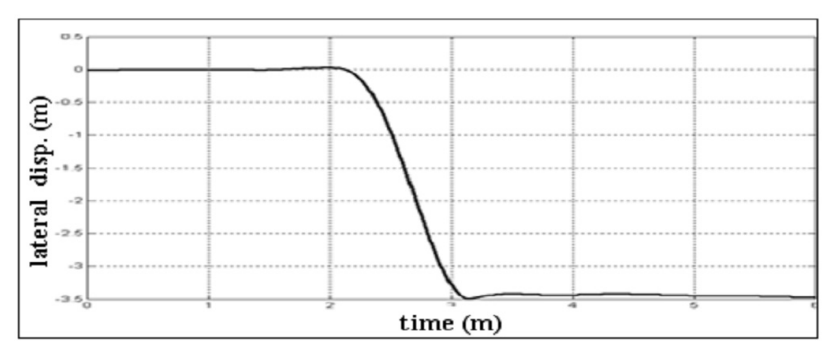

(a) lateral trajectory

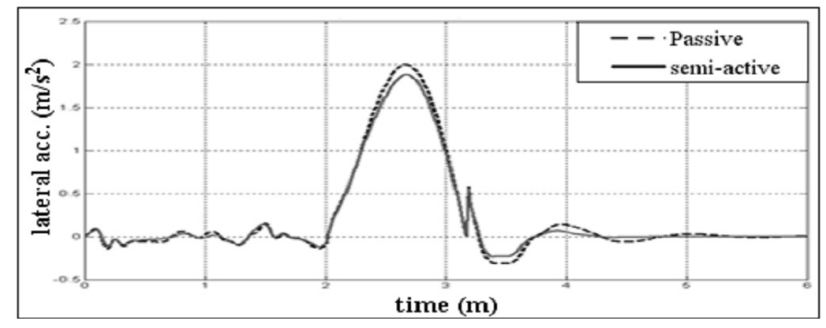

(b) lateral accleration

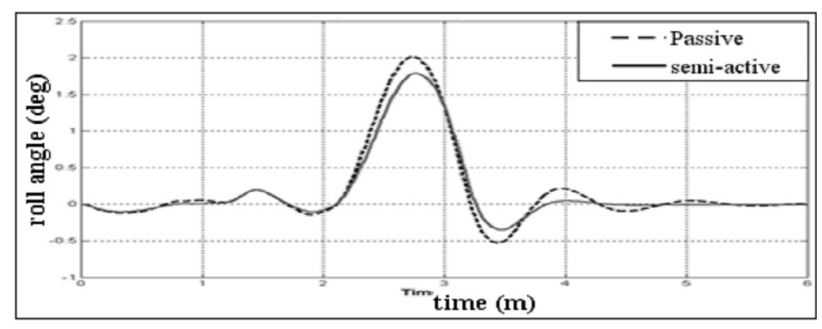

(c) roll angle

Fig. 12 Single lane change simulation results: (a) lateral trajectory (b) lateral acceleration (c) roll angle

12(b)와 (c)에서 보여주는 바와 같이 MR댐퍼를 장착한 차량이 수동 댐퍼를 장착한 차량 보다 횡 방향 가속도와 롤 각 모두에 서 작은 진폭을 보여주었다. 또한 $\mathrm{MR}$ 댐퍼를 장착한 차량이 수동 댐퍼를 장착한 차량에 비해 좀 더 빠르게 안정화 되었다.

\section{6. 결 론}

본 논문에서는 MR 댐퍼를 장착한 대형버스 현가장치의 반 능동 제어에 관한 연구를 수행하였다. 개량된 Bouc-Wen 모델 을 대형버스에 적합하도록 수정하여 $\mathrm{MR}$ 댐퍼 모델로 이용하 였다. MR 댐퍼를 장착한 대형버스 현가장치의 반능동 제어를 위하여 퍼지 제어기를 개발하였다. MR 댐퍼가 장착된 지점에 서 수직 가속도와 스프렁 상 질량과 하 질량 사이의 상대 속도 를 입력 변수로 사용하였다. 그리고 전압을 출력 변수로 사용하 였다. 컴퓨터 차량 모델과 MR 댐퍼 및 퍼지 제어기를 MSC. $\mathrm{ADAMS} / \mathrm{Control}$ 모듈을 이용하여 통합하여 모의시험에 이용 하였다. 본 논문에서는 수동 현가장치와 MR댐퍼를 이용한 반 능동 현가장치의 승차성능을 비교하기 위하여 랜덤 노면 형상
을 가지는 노면과 범프를 통과하는 직진주행 모의시험을 수행 하였다. 랜덤 노면 형상을 가지는 노면에서는 $70 \mathrm{~km} / \mathrm{h}$ 와 $60 \mathrm{~km} / \mathrm{h}$ 의 속도로 모의시험을 수행하였고 범프 통과 모의시험은 $40 \mathrm{~km}$ $/ \mathrm{h}$ 와 $30 \mathrm{~km} / \mathrm{h}$ 의 속도로 수행하였다. 이 같은 직진 주행 모의시 험을 통해 $\mathrm{MR}$ 댐퍼를 장착한 차량이 수동댐퍼를 장착한 차량 에 비해 수직가속도와 피치 각에서 진동의 진폭이 좀 더 작을 뿐 아니라 좀 더 빨리 안정화됨을 보였다. 랜덤 노면 형상에서 수행한 모의시험에서 MR 댐퍼를 장착한 반능동 현가장치의 수직 진동 제진 효과가 $70 \mathrm{~km} / \mathrm{h}$ 보다는 $60 \mathrm{~km} / \mathrm{h}$ 에서 뚜렷하였 다. 또한 범프 통과 모의시험에서 수직진동과 피치 각 제진 효 과가 $30 \mathrm{~km} / \mathrm{h}$ 보다는 $40 \mathrm{~km} / \mathrm{h}$ 에서 크게 나타났다. 핸들링 성능 을 비교하기 위한 단일 차선 변경 모의시험에서 $\mathrm{MR}$ 댐퍼를 장 착한 차량이 수동 댐퍼를 장착한 차량 보다 횡 방향 가속도와 롤 각 모두에서 좀 더 작은 진폭을 보여줄 뿐 아니라 좀 더 빠르 게 안정화 되는 것을 보여주었다.

\section{References}

(1) Nam, H. M., 2000, "Performance Characteristics of Seat Damper Using MR Fluid," KSMTE, Vol. 9, No. 6, 127 134.

(2) Karnopp, D., Crosby, M., and Farwood, R., 1974, "Vibration Control using Semi Active Force Generators," ASME J England, Vol. 96, No. 2, pp. 619 626.

(3) Yao, G. Z., Yap, F. F., Chen, G., LI, W. H., and Yeo, S. H., 2002, "MR Damper and its application for Semi Active Control of Vehicle Suspension System," Mechatronics, Vol. 12, No. 7, pp. 963 973.

(4) Haiping, D., Kam, Y. S., and James, L., 2005, "Semiactive $\mathrm{H} \sim$ Control of Vehicle Suspension with Magnetorheological Dampers," Journal of Sound and Vibration, Vol. 283, No. 3 5, pp. 981 996.

(5) Michele, I., Patrizio, T., and Mauro, M., 2006, "Development of a Heavy Truck Semi-Active Suspension Control," Control Engineering Practice, Vol. 14, No. 3, pp. 305 312.

(6) Beak, W. K., Yang, B. S., Lee, J. S., Kim, T. H., and Ryu, S. W., 2005, "1/4 Car Vibration Simulation Using an Empirical MR Damper Model," Journal of KSNVE, Vol. 15, No. 9, pp. 1016 1022.

(7) Lee, H. S., Choi, S. B., and Lee, S. K., 2000, "Vibration Control of a Passenger Vehicle Featuring MR Suspension Unit," Journal of KSNVE, Vol. 11, No. 1, pp. 41 48. 
(8) MSC.ADAMS, viewed 2001, ADAMS User's Manual, MacNeal-Schwendler Inc.

(9) MATLAB, viewed 2000, SIMULINK, Dynamic System Simulation for MATLAB, The Mathworks Inc.

(10) MATLAB/Fuzzy Logic Toolbox, viewed 2001, MATLAB /Fuzzy Logic Toolbox User's Manual, The Mathworks Inc.
(11) Spencer Jr, B. F., Dyke, S. J., Sain, M. K., and Carson, J. D., 1997, "Phenomenological Model of a Magnetorheological Damper," J. Eng. Mech., Vol. 123, No. 3, pp. 230 238.

(12) Wen, Y. K., 1976, "Method of Random Vibration of Hysteretic Systems," Journal of Engineering Mechanics Division, ASCE, Vol. 102, No. 2, pp. 249 263. 